\title{
Influencing the direction of innovation processes: the shadow of authorities in demand articulation
}

\author{
Haico te Kulve, ${ }^{1 *}$ Wouter Boon, ${ }^{2}$ Kornelia Konrad ${ }^{1}$ and \\ Tjerk Jan Schuitmaker ${ }^{3}$
}

\author{
${ }^{1}$ Science, Technology and Policy Studies, University of Twente, PO Box 217, 7500 AE, Enschede, The Netherlands, \\ ${ }^{2}$ Innovation Studies Group, Copernicus Institute Sustainable Development, Utrecht University, Heidelberglaan 2, \\ 3584 CS Utrecht, The Netherlands and ${ }^{3}$ Athena Institute, VU University Amsterdam, De Boelelaan 1085, 1081 HV, \\ Amsterdam, The Netherlands \\ *Corresponding author. Email: h.tekulve@utwente.nl \\ ${ }^{\dagger}$ Contribution to special issue Science and Public Policy 'The next generation of innovation policy: Directionality \\ and the role of demand-oriented instruments'.
}

\begin{abstract}
This article aims to contribute to the development of demand-based innovation policies by examining the role of regulatory authorities in the process of formulating demands and requirements for novel technologies in three specific cases of emerging sensor technologies. We make two contributions. First, we conceptualize the different ways in which authorities may be involved in demand articulation processes during the innovation journey. We suggest four potential roles for regulatory actors: 'following authority', 'forceful authority', 'co-creating authority' and 'shadow authority'. Second, we show how regulatory authorities in their role of 'shadow authority' influence demand articulation processes even if they are not immediately engaged. In early phases of the innovation journey, regulatory agencies may not be directly involved, but suppliers and potential users of technologies anticipate authorities' positions and actions. In conclusion, we discuss the situations in which the involvement of regulatory authorities can support the process and guide the direction of demand articulation.

Key words: demand-based innovation policy; demand articulation; regulatory agencies; sensors; microtechnology; nanotechnology; ecogenomics
\end{abstract}

\section{Introduction}

Increasingly, demand-side intervention strategies in innovation processes are of interest in academic and policy circles (Edler 2013; Edler and Georghiou 2013; OECD 2011). ${ }^{1}$ Governments apply demandside innovation policies in cases of market or systemic failures as a means to stimulate economic growth or address particular societal challenges (Edler 2013). The formulation and specification of user preferences and requirements, i.e. demand articulation (Boon et al. 2008), has been recognized as a key element within demand-based innovation policies and in foresight activities initiated by governmental actors (Edler 2013; Georghiou and Harper 2011). For example, in the fields of nanotechnology and genomics, public actors play a visible role in the construction of expectations on their potential economic and broader societal benefits, thereby contributing to agenda-building and the creation of demand for such novelties.
In the literature on demand-based innovation policies, the dynamics of demand articulation and the role of public actors therein is, however, under conceptualized. Regulatory authorities in particular, as one category of public actors, are not immediately associated with notions like user preferences and requirements. They do not feature as important purchasers of novel technologies and are often not visibly involved in early phases of the innovation journey and the linked demand articulation processes. Still, innovation is not only about novelty creation, but also about the implementation of novelties (Garud et al. 2013; OECD 2005). In many sectors like healthcare, water and energy, authorities contribute significantly to the implementation phase of new technologies. They contribute to translating laws and directives into guidelines that are used to define the requirements to which products need to adhere. 
Much research on the interactions between regulation and innovation has focused on the positive or negative influence of regulatory action on innovative output (Blind 2016), for instance on the basis of indicators like patents (Jaffe et al. 2002). This body of literature has drawn attention to the contextualized nature of the role of regulations in innovation, taking into account differences between, e.g. sectors (Ambec et al. 2013; Kemp and Pontoglio 2011; Porter and Van der Linde 1995). However, this research has focused on established industries, less so on the formulation of regulatory requirements and preferences concerning emerging technologies. In discussions about regulating emerging technologies such as nanotechnologies, the regulation of risks (in face of uncertainty), rather than influencing the contents of nanotechnologies, seems to be the main preoccupation.

In this article, we explore the following research question: to what extent and in what way do (public) regulatory authorities influence demand articulation processes? In particular, we examine the way in which authorities affect the legitimacy of demands for new technologies and how they affect the specification of requirements for such technologies. Insights into the role of these public agencies contribute to a better understanding of where and how to stimulate demand articulation and of the linkages between demandbased innovation policies and other governmental policies. We examine and contextualize the role of regulatory agencies via three case studies on emerging sensor technologies. These sensors are aimed at measuring the quality of drinking water, food and beverages, and soil, and they are based on emerging technologies, i.e. micro/nanotechnologies and ecogenomics. Thus, all cases are instances of emerging technologies with a high degree of uncertainty regarding their future performance and demand, and with applications in highly regulated domains.

We position our paper within a call by Edler (2003) to deepen our understanding of demand-based innovation policy instruments oriented toward the regulation of demand or toward the demandproducer interface. Insight into the role of regulatory authorities in demand articulation supports technology producers, users and regulatory agencies in managing their involvement in demand articulation. First, we conceptually elaborate our argument as to why and how regulatory agencies contribute to, and can be involved in, demand articulation processes. Second, we explore this empirically for cases of emerging technologies. Third, we draw some implications for demand-based innovation policies about the involvement of regulatory authorities to support the demand articulation and directionality of innovation processes.

In the next section, we present the conceptualization of demand articulation and the roles that regulation and regulatory agencies can play in these processes. Section 3 presents the methods used, and Section 4 studies these processes in three empirical cases: sensors for measuring the quality of drinking water, food and beverages, and soil. Finally, Section 5 discusses the results and highlights the conclusions.

\section{Demand articulation and the role of regulatory agencies}

\subsection{Demand-based innovation policies and demand articulation}

Demand articulation is 'an iterative, inherently creative process in which stakeholders try to unravel preferences for and address what they perceive as important characteristics of an emerging innovation' (Boon et al. 2008: 645). Preferences and requirements regarding novel technological options are not a given. Rather, they are actively constructed, evolve and may give rise to new innovation trajectories (Christensen 1997; McMeekin 2001; Tripsas 2008). Demand involving novel technologies is constructed during interactions between users and suppliers (Leonard-Barton 1988; Rip 1995) and includes learning about (future) technologies and actor perspectives regarding these technologies.

The evolving character of demand is particularly visible in cases of emerging technologies, such as nanotechnology and genomics. Emerging technologies are associated with high expectations regarding their potential to contribute to societal challenges in domains of for instance food, healthcare, energy and the environment. At the same time, various aspects of emerging technologies remain fluid and malleable (Rip et al. 1995; van Merkerk and van Lente 2005) on both the supply and the demand side. Indeterminacies and uncertainties in such processes impede exploration of the use potential and conditions for implementation (Deuten et al. 1997). Uncertainties in demand articulation extend beyond the point of purchase of new products and also include the implementation or domestication of new products by business users or consumers, as reflected in the term 'innofusion' (Fleck 1988). In this understanding of demand articulation, it becomes clear that the broader environment including authorities is also involved at different stages of innovation processes (Te Kulve and Konrad 2017).

Clearly, users, producers and regulators assess novel technologies in different ways. These actors have different socio-cognitive positions (Garud and Ahlstrom 1997), and this complicates 'matching' or aligning perspectives. Conflicts may emerge about which preferences and requirements are desirable or legitimate. Developers and producers of new options will act as 'enactors' (Rip 2006), emphasizing benefits and advantages, whereas users and regulatory agencies take other options into account and act as 'comparative selectors'. Approaches such as Constructive Technology Assessment have been developed to organize interactions between these different social groups to voice their preferences and proactively involve them in innovation processes (Schot and Rip 1997; Rip and Te Kulve 2008; Te Kulve and Rip 2011). In our empirical research, we draw upon this approach to collect data and understand what is happening.

In cases of emerging technologies, both the supply of, and the demand for, new technological options are associated with uncertainties. One consequence of this is that users and producers do not have sufficient information to be able to make robust decisions on the future adoption of innovations. These so-called information asymmetries form one central rationale for public policy in general and demand-side innovation policy in particular (Edler 2003). Others have called this demand articulation failure, reflecting 'a deficit in anticipating and learning about user needs' (Weber and Rohracher 2012: 1043). We add that users also do not always know what is technologically possible.

Demand articulation failure leads to inefficiencies in innovation systems. For example, when user needs are unknown or unclear at the start, technological development trajectories might result in innovative solutions that are societally unacceptable or simply redundant. Moreover, the creative potential of users is not incorporated into the innovation. Uncertainties about demand, in combination with uncertainties regarding the future performance of emerging technologies, may lead to impasses or waiting games (Te Kulve 2010; Parandian et al. 2012) in innovation processes.

Demand articulation failure and its detrimental impact on innovation and potential economic growth provides the state with a 
rationale for supporting private and public demand directly via procurement and indirectly through mobilizing, informing and connecting (Edler 2003). States already influence the direction of innovation processes, as convincingly argued by Mazzucato (2013). Especially in early stages with high uncertainties of technological performance and future demand, states play a key role. Concretely, regarding our topic of demand articulation, public actors can choose to invest more heavily in facilitating such processes. It may also imply a more direct involvement of public actors in demand articulation processes.

Public actors such as regulatory agencies can be involved in different ways in forming demand. Blind (2016) surveyed different types of regulation of demand or regulation of the user-producer interface. Types of regulation include regulation of product performance and manufacturing, regulation of product information, process and usage norms, support of innovation-friendly private regulation activities, and regulations to create a market. These different types of regulation are useful in mapping the contents of processes involving regulatory authorities and demand. In the following section, we further elaborate this by conceptualizing how regulatory authorities are involved in such processes, thereby adding a more dynamic perspective of particular relevance for our study.

\subsection{Demand articulation processes in the interplay between users, producers, and regulators}

When studying demand articulation taking place in the interplay of users, producers, and regulators, we specifically want to elaborate on the relationships between these actor groups. First, the relationship between regulators and producers has been the subject of study in innovation policy literature over the last decades. Regulation is regarded as having ambivalent effects on innovation (Blind 2016). Laws are partly considered to constrain economic actors in their actions and distort the functioning of markets (North 1984; Macgregor et al. 2000). Since Porter and Van der Linde's (1995) pivotal article, more attention has been paid to the positive influences of regulation as well; see also Mazzucato (2013). Porter and Van der Linde present a list of arguments as to why regulations may be beneficial to innovation in the field of environmental technologies. Besides regulations that facilitate markets and address market failures, such as intellectual property rights, standards, and even restrictions can have a positive influence on enterprise. These regulations can provide certainty for firms operating in a particular sector.

Especially in the context of emerging technologies, more certainty on regulation can be beneficial: emerging technologies such as genetically modified organisms (GMOs) and nanotechnology are associated with a high degree of uncertainty on e.g. technical, market-demand, infrastructure, and ethical dimensions. Producers might therefore value some assurances: 'regulation can provide an important source of legal clarity about liability highly valued at the early, uncertain stages of technology development' (Lowe and Feldman 2008).

The influence of regulators in early stage developments is nicely illustrated by Martin's study of the development of gene therapies (Martin 2001). According to Martin, the emergence of a dominant vision was not the result of technological superiority, but rather because the emerging leading option, delivery of genes through drugs, was closer to existing regulated medical practices and was found more appealing by potential users. The alternative option, ex vivo cell therapy, required the development of new clinical practices, which also still had to be accepted by the FDA. This generated large commercial and regulatory uncertainties for firms, and the ex vivo approach would eventually be abandoned.

Producers are also proactively engaged with the formulation of regulations. This has been the subject of work in the corporate political activities literature (Hillman et al. 2004), which focuses on how companies can obtain competitive advantage by engaging in political activities. Oliver and Holzinger (2008) argue that businesses can have two types of value perspectives: either they maintain current activities or they change and innovate. When choosing to innovate, businesses can comply with current or upcoming regulations and therefore gain a fast-mover advantage or they can proactively aim to change regulations through political activities. Firms may also dedicatedly create new standards that will shape activities in a particular industry, as Garud and colleagues showed in the context of information technology (Garud et al. 2002). New standards may subsequently create novel, legitimized social practices associated with regulation uptake (Garud and Rappa 1994).

Alternatively, changes in institutions, including regulatory regimes, can contribute to changes in users' preferences and requirements. As pointed out by Tripsas: 'shifts in the sociopolitical environment including regulatory change, new legislation, political turmoil, or other exogenous shocks, can alter user preferences [...] Finally, proactive moves on the part of producer firms to shape preferences through media and industry institutions can shift customer willingness to pay for given attributes' (2008: 80). Tripsas' point highlights the phenomenon of dedicated actors who aim for changes in the institutional environment; this in turn influences customer preferences. This is nicely illustrated in Munir and Philips' (2005) study on Kodak's introduction of the portable roll-film photo camera.

We want to highlight two interrelated aspects here. First, demand articulation is distributed across a variety of actors, including regulatory authorities. Users and producers of novel technologies are 'embedded' in specific technology developments (Garud and Karnøe 2003) and broader institutional and regulatory structures (Te Kulve and Konrad 2017) in which they and other actors such as authorities become interwoven. Second, being embedded in broader societal structures and institutions, such as a particular regime prescribing measurement and monitoring approaches, leads users and producers to take such structures and institutions seriously. We expect that users and producers will anticipate positions of other actors such as regulatory authorities whether involved or not, and whether the newly emerging technologies and their use will fit with existing practices or not. Or, users and producers may engage in modifying regulatory schemes. From the perspective of regulatory authorities then, they may or may not be directly engaged in demand articulation. Regulations under their responsibility may or may not be modified. In the following section, we conceptually elaborate the involvement of authorities in demand articulation.

\subsection{Involvement of regulatory authorities in demand articulation}

On the basis of our discussion on interactions between users, producers and regulators, and the role of regulations in demand articulation processes, we propose to distinguish between different modes of regulator involvement. ${ }^{2}$ These modes are defined by two dimensions: the level of regulators' engagement with demand articulation (horizontal axis) and the level of stability of regulations (vertical axis). When combining these dimensions, we suggest four potential roles for regulatory actors: following authority, forceful authority, co-creating authority, and shadow authority (Fig. 1). 


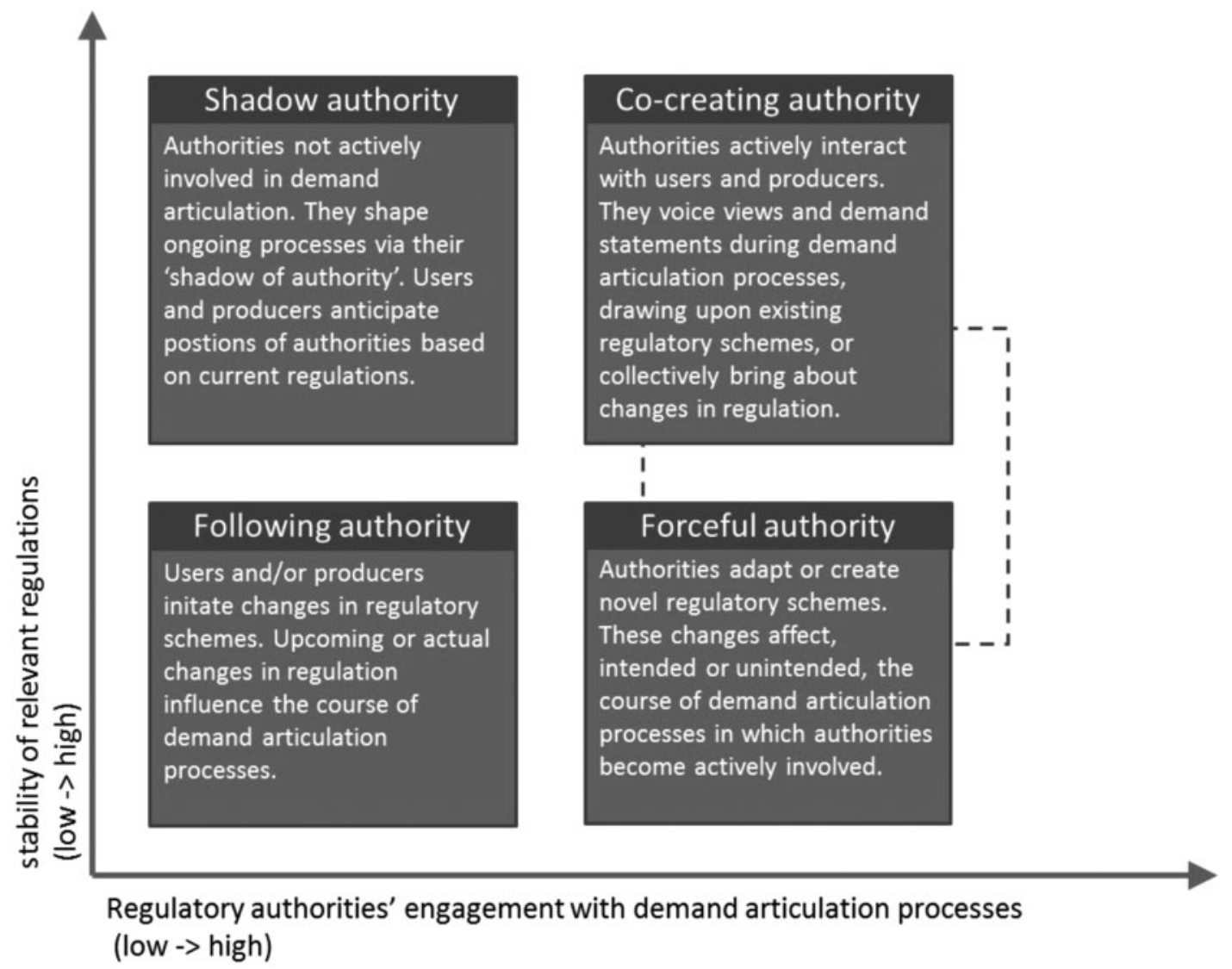

Figure 1. Potential roles of regulatory authorities in demand articulation.

If existing regulations do not fit with the workings of the envisioned emerging technologies or are considered to produce undesirable impacts, users, and producers may have an interest in changing regulatory schemes. Authorities may not immediately take the initiative, because there is no perceived societal need or they prefer to wait until more data are available regarding the performance of the new technologies. In such cases, authorities may be convinced to follow users' and producers' initiatives because they are convinced of their use or to stimulate innovation (following authority). The case of HFC 134a, a refrigerator coolant, is an example where regulators followed. Industry developed a technological alternative to CFC because of scientists' and environmentalists' concerns regarding the impact of CFCs on the ozone layer. This enabled governments to eventually ban CFCs (because there was an alternative) (Van de Poel 2003).

Authorities can also be more pro-active and force the development of new preferences and requirements through new legislation (forceful authority). A well-known example is the introduction of the clean air act legislation in the USA that prescribed car emission standards that were more stringent than what could be achieved by current technologies (Gerard and Lave 2005). This is a case of forcing technology to push the development of new technologies to, ideally, fulfill societal needs.

In cases of emerging technologies in application domains where regulations are taken into account as 'business as usual', authorities may remain in the background. Regulations may serve as an important reference point, especially when the new technologies do not challenge them or when there is no outspoken perceived societal need to change regulations. This may be the default situation for many emerging technologies. Although regulatory authorities may not be prominently involved in demand articulation, their influence is still visible in involved actors' considerations (shadow authority).

The indirect role of authorities influencing processes where embedded actors interact shares similarities to what Scharpf (1994, 1997) has called the shadow of hierarchy in situations of nonhierarchical decision-making. Scharpf claimed that non-hierarchical co-ordination or self-coordination works in situations where these negotiations are embedded in a hierarchical context, i.e. where a governmental actor has the final authority, see also Börzel and Risse (2010). Our point here is not about co-ordination, but about the indirect influence of authorities in demand articulation. In situations of emerging technologies in highly regulated domains such as for instance pharmaceutical treatments, authorities may not be prominently involved in the early stages of the innovation journey. Still, actors' involved in that journey will likely anticipate authorities' evaluations regarding the novel product, as shown by Martin (2001). Through their shadow of authority, regulatory authorities contribute to the governance of innovation at the demand-sidedemand articulation processes-even if unintentionally.

Regulatory authorities can remain in the background, but they can also be more actively involved in demand articulation processes without changing regulatory schemes (co-creating authority). One reason to do so in the case of emerging technologies is for authorities to be informed about possible new technologies that are on the brink of passing existing regulations, for instance in the case of new pharmaceutical treatments. An important issue there is to ensure 
Table 1. Characterization of the cases

\begin{tabular}{|c|c|c|c|}
\hline Case & Monitored goods & Actor constellation & $\begin{array}{l}\text { Regulatory authorities' involvement with moni- } \\
\text { tored goods }\end{array}$ \\
\hline Drinking water & $\begin{array}{l}\text { Hybrid good } \\
\text { (public/private } \\
\text { mix) }\end{array}$ & $\begin{array}{l}\text { Concentrated sector, short value chain, nation- } \\
\text { ally oriented Co-operative relationship be- } \\
\text { tween business users of sensor technologies }\end{array}$ & $\begin{array}{l}\text { Inspection of sources, intermediate and end } \\
\text { products. Specific prescription of measure- } \\
\text { ment parameters and procedures }\end{array}$ \\
\hline Food \& Beverages & Private goods & $\begin{array}{l}\text { Fragmented sector, long value chain, strong } \\
\text { international links. Competitive Relationship } \\
\text { between business users of sensor technologies }\end{array}$ & $\begin{array}{l}\text { Inspection of products along the value chain, } \\
\text { prescribing specific measurement parameters } \\
\text { and procedures }\end{array}$ \\
\hline Soil & Public good & $\begin{array}{l}\text { Sector with limited players, nationally oriented. } \\
\text { Competitive relationship between business } \\
\text { users of sensor technologies }\end{array}$ & $\begin{array}{l}\text { Inspection, general frame suggestion measure- } \\
\text { ment methods }\end{array}$ \\
\hline
\end{tabular}

that these new treatments meet regulatory guidelines. Authorities may give advice to firms, which may subsequently adjust their requirements to their upstream suppliers. In principle, this more interactive role of authorities may also lead to joint efforts to bring about changes in regulatory schemes (the dotted lines in Fig. 1).

The effect of regulatory authorities' involvement will differ depending on their roles, their relationship with the domain and the type of goods involved in demand articulation. We can specify this further by differentiating between the types of impacts of their involvement. Regarding the type of impacts, we distinguish between symbolic and more operational impacts.

Symbolically, regulatory actors' involvement through their voiced views and perspectives, or through the regulation referred to, can affect demand articulation in two ways. First, it can affect the perceived legitimacy of demands associated with a technology. Second, it can influence which demands are put on the agenda of organizations or a field at large. For example, the question could be whether regulatory agencies believe there is a need to introduce new technologies in a particular sector and whether the sector should foster such technologies. The notion of symbolic impact is related to considerations on input and output legitimacy of demand-side innovation policy, as discussed by Boon and Edler (2018).

At a more operational level, regulatory actors' involvement can affect the specification, opening up or closing down of preferences for new technologies and their implementation. For instance, what are the specific requirements and conditions for measurement technologies to be accepted by regulatory authorities?

When treating the cases, we examine these symbolic and operational aspects of authorities' involvement in demand articulation in answering the question of the extent to which and how (public) regulatory authorities influence such processes. Our analysis of the cases consists of the following steps: (1) we identify driving forces in demand articulation in the domain, including technologies and regulatory authorities' involvement; (2) we examine the legitimacy of new sensors (symbolic impact); (3) we examine the specification of sensor requirements and authorities' involvement (operational impact); and ultimately (4) we discuss the role of regulatory authorities (referring to Fig. 1).

\section{Research sites and methods}

To examine the role of regulatory authorities in demand articulation for novel technologies, we selected cases for which we expected their role to be highly visible. Therefore, all our cases are instances of emerging technologies with a high degree of uncertainty regarding their future performance and demand, and with applications in highly regulated domains. We chose to focus on cases within the area of sensor technologies for reasons of comparability. Furthermore, we selected cases that differed in terms of actor constellations, types of goods and extent of regulators' involvement in order to create analytical variety. We expected that the type of goods and the relationship of regulatory agencies with the field might elicit different involvement/responses from regulatory agencies and that differences in actor constellations would generate different dynamics in demand articulation. In Table 1 , we offer a characterization of our cases.

We gathered a rich dataset describing statements about demand (e.g. preferences) of actors involved in sensor development. We conducted interviews with knowledge institutes and affiliated start-ups, sensor suppliers, users of sensors, authorities, and whenever possible also public interest groups. In the interviews, we discussed views on sensor applications and asked further about the motivations and considerations behind participants' views. We focused on contemporary developments in demand articulation, but where appropriate asked participants about positioning current developments in time. In addition, we asked what interviewees felt was important for the further development and embedding of sensors in organizational practices. The interviews lasted about 60 minutes each and were transcribed. In our content analysis of the transcripts, we examined what and whom the interviewees were taking into account in the formulation of their preferences and requirements.

In addition, we organized interactive workshops that brought together actors involved in sensor technologies and applications. The aim of the workshops was to discuss participants' preferences regarding sensor applications and strategies to stimulate the implementation of sensor technologies. The moderated workshops can be characterized as a particular kind of focus group. To design the workshops, we drew upon Constructive Technology Assessment methodologies (Rip and Te Kulve 2008; Te Kulve and Rip 2011). The key element of these methodologies is to convene a set of participants who represent different actor positions in an organizational field and orchestrate discussions in such a way that participants learn from one another's perspectives and considerations. We thus created a microcosm closely resembling the domains of drinking water, soil, and food and beverages. To support anticipation of future dynamics related to demand articulation and implementation of sensors, two (drinking water and food and beverages) of the three workshops made use of scenarios crafted in advance of the workshops. For an overview of the interviewees and workshop participants, see Table 2.

We focused on examining actors' possible different perspectives on the application of sensor technologies and how actors' embeddedness in a particular domain influenced their assessment of 
Table 2. Overview of interview and workshop participants

\begin{tabular}{|c|c|c|c|c|c|c|c|}
\hline Cases & $\begin{array}{c}\text { Interviews \& } \\
\text { Workshops }\end{array}$ & $\begin{array}{l}\text { Knowledge } \\
\text { institutes }\end{array}$ & $\begin{array}{l}\text { Sensor } \\
\text { suppliers }\end{array}$ & $\begin{array}{l}\text { Users (firms, } \\
\text { laboratories) }\end{array}$ & $\begin{array}{l}\text { Governmental / } \\
\text { standardization } \\
\text { organization }\end{array}$ & $\begin{array}{l}\text { Public } \\
\text { interest } \\
\text { group }\end{array}$ & Total \\
\hline \multirow[t]{2}{*}{ Drinking water } & Interviewees & 3 & 4 & 5 & 1 & 1 & 14 \\
\hline & $\begin{array}{l}\text { Workshop } \\
\text { participants }\end{array}$ & 3 & 4 & 5 & 3 & - & 15 \\
\hline \multirow[t]{2}{*}{ Food \& Beverages } & Interviewees & 4 & 4 & 4 & 2 & - & 14 \\
\hline & $\begin{array}{l}\text { Workshop } \\
\text { participants }\end{array}$ & 5 & 3 & 2 & 2 & - & 12 \\
\hline \multirow[t]{2}{*}{ Soil } & Interviewees & 2 & 2 & 3 & 4 & 2 & 13 \\
\hline & $\begin{array}{l}\text { Workshop } \\
\text { participants }\end{array}$ & 10 & 5 & 22 & 11 & - & 48 \\
\hline
\end{tabular}

emerging sensor technologies. In our analyses, we followed the four elements mentioned in Section 2: (1) driving forces in demand articulation, (2) legitimacy of new sensors, (3) specification of sensor requirements and the involvement of authorities, and (4) role of regulatory authorities. In particular, we examined how regulatory authorities were involved or were taken into account in actors' assessments in our interviews and workshops. The use of a combination of interviews and workshops provided the opportunity to triangulate data and decrease the risk of bias toward sociallydesirable answers in either workshops or interviews.

\section{Case studies}

\subsection{Sensors for drinking water quality}

4.1.1 Driving forces in the domain and concerning technologies The drinking water sector in the Netherlands is heavily regulated, concentrated within a few companies and owned by public shareholders. Intake of water, purification, and distribution is integrated in a single company in a particular geographical area. Measurement of water quality parameters is either outsourced to drinking water laboratories or provided in-house.

To assure and control drinking water quality, regulations exist at both national and EU level. Regulations specify which parameters have to be measured, maximum values allowed, frequency, and location of measurements (predominantly at the tap, but also at the source or during production), and measurement methods. ${ }^{3}$ If contaminations exceed allowed values, water companies may decide to temporarily stop water intake, advise consumers to boil water before consumption, flush contaminated distribution pipes and so on.

The detailed regulation of water quality monitoring offers a strong reference point regarding preferences and requirements for novel monitoring technologies. The supply of, and access to, clean drinking water is considered a public service in the Netherlands. Regulatory authorities may thus exert a powerful influence on the direction of demand articulation processes in this domain. The structure of the sector supports interactions and negotiations in demand articulation, because the drinking water sector is wellorganized and the number of players is limited. However, in terms of governance, drinking water companies have some room to maneuver. First, drinking water companies operate relatively autonomously. They also have additional monitoring processes in place, including sensors, beyond what is legally required; this indicates a pro-active attitude on their part. In addition, the Dutch drinking water sector has a history of favoring bottom-up collaboration between companies rather than top-down induced cooperation
(Hegger et al. 2011). Regulatory authorities are not likely to be actively involved in negotiating preferences and requirements regarding new monitoring technologies. Thus, we may expect a shadow authority role here.

The development of sensors in order to measure (nearly) realtime water quality has a history. As far back as the 1960s, a variety of technologies had been developed to monitor water parameters. A number of sensors, such as devices to monitor $\mathrm{pH}$ or turbidity, are broadly applied by water utilities worldwide (Van den Broeke et al. 2014). Currently, advances in the fields of micro- and nanotechnologies promise to deliver sophisticated devices to measure water quality. With real-time insight into water quality, users of such devices are supposed to be able to intervene more rapidly in the intake, production, distribution, and consumption of water. The type of sensors preferred and required by users depends on the envisaged application of such sensors. Here, we concentrate on the use of sensors in the context of managing and assuring drinking water quality. In practice, this means that sensors can be used at various stages of the clean drinking water supply chain: at source (intake areas of surface waters), production (water purification plants), distribution (thousands of kilometers of piping), and the point of consumption (households, industries, agriculture, hospitals, restaurants, and so on).

\subsubsection{Legitimacy of new sensors}

Drinking water in the Netherlands is generally regarded as of high quality. Drinking water companies are highly motivated to uphold this image-an image confirmed by studies on consumer views. These studies also show that high drinking water quality is taken for granted by consumers and is generally not seen as a topic for concern, needing additional actions (Van der Kooij et al. 2010).

The absence of pressure from consumers and the high quality of drinking water mean that there is no pressing need for sensors to be introduced. For policymakers involved with drinking water regulations, new sensor technologies are seen as interesting, but currently not prominent on the agenda. For them, the existing approach-a monitoring regime prescribing the measurement of specific contaminants-remains important, also because this is prescribed by European regulations. Thus, there is no forceful authority role for regulatory agencies here.

Even if authorities are not much involved in demand articulation, governmental agencies have been important in generating attention on new monitoring technologies. The attacks on 11 September 2001 in the USA led to a range of policies regarding security, including securing critical infrastructures such as the drinking water supply. This led not only to physical measures (gates and 
fences) but also to (renewed) interest in developing rapid monitoring technologies. Various projects have been initiated, sometimes co-funded by public agencies, to research sensor technologies for drinking water applications. In fact, part of the legitimacy of sensors derives from the perceived need to be better prepared for possible malicious contamination of the drinking water supply. The limited involvement of regulatory authorities, then, does not mean that sensors are not on the agenda in the drinking water sector. In the Netherlands, a number of pro-active water utilities have been involved in research projects developing new sensor technologies. These water utilities and knowledge institutes believe that sensors offer great improvements to the currently relatively slow monitoring techniques. This view is not shared by all utilities, as some of them prefer to follow developments or are skeptical about the application of sensors in the distribution network, particularly if regulations do not require additional monitoring.

Perceptions of regulatory schemes and anticipations of authorities' positions are part of the considerations of water utilities. The shadow role of authorities is visible, but does not determine preferences. Current regulations, with their specific prescription of monitoring approaches, do not easily allow for novel monitoring technologies such as sensors. Such new measurement technologies first need to prove to be equal or better in performance than the prescribed approaches. Water utilities that explore sensor technologies are well aware of these conditions, but explore sensor technologies nonetheless. They expect that they, together with other utilities, may convince the authorities (and skeptical utilities) to use sensor technologies, when these are shown to be effective. In other words, they anticipate a following authority role in the future.

\subsubsection{Specification of requirements}

Besides the basic idea of using sensors being to some extent a topic for debate, several routes are being explored to specify sensor requirements. Sensors are being developed to measure specific parameters such as deviations in water quality or toxic effects. The current monitoring regime is reflected in the emergence of sensors that measure deviations in water quality rather than specific contaminations. This is a relatively recent development since the mid-2000s and breaks with the prevailing focus on increasing the variety and sensitivity of possible monitored contaminants. Given the large variety in contaminants, it has proved difficult to develop a sensor that could capture all. In addition, sensor experts believe that sensor technologies will not be able to reach the levels of sensitivity required by regulatory authorities. This implies that such sensors will not be able to perform as well as existing equipment and therefore cannot replace them. This undermines the legitimacy of the use of sensors in cases where high sensitivity is required. This disadvantage inspired researchers to develop alternative monitoring approaches that measure general deviations rather than specific contaminants. This is a further indication of the continuing shadow role of authorities in guiding demand articulation processes.

Convincing water utilities and authorities of the validity, robustness, and reliability of new sensors is a recurring item in discussions on requirements for novel sensors. Negative experiences with sensor development and application in the past have made water companies cautious about trusting new sensors. Great emphasis is placed on their robustness, validation, and certification. This emphasis can partially be explained by negative experiences in the past. It also relates to the preference to include new sensors in regulatory schemes. Advocates of sensor technologies believe that regulation will eventually be adapted on the basis of new technological possibilities, just as current regulations are based on measurement capabilities in the past. Validation requires considerable efforts and resources that may not easily be mobilized within the sector. Certification is difficult, as current standards may not be compatible with novel measurement principles employed by sensor technologies. Then, new standards for real-time or rapid test measurement technologies are required. Further specification of sensor technologies is currently constrained by the uncertainties regarding validation, certification, operational use, and relation with monitoring regulations. During the workshop and interviews, relationships with policymakers in this area were seen as critical in furthering the development and introduction of novel sensor technologies. In other words, regulatory authorities can be expected to play a more important role in a later phase of sensor innovation.

\subsubsection{Role of regulatory authorities}

In the case of drinking water, the role of authorities can best be characterized as one of a shadow authority. First, regulatory authorities are not actively engaged as they for instance do not stimulate demands for new sensor technologies by pushing them on the sector's agenda. This is a more general trend in the drinking water sector; given the relationship between authorities and the drinking water sector, authorities stay in the background rather than interfere directly with demand articulation processes. As we have shown in our study though, other parts of the government may play an important role in stimulating sensor technologies as part of improved security of vital infrastructures. Second and related, authorities do influence demand articulation, even if they are not actively engaged. Sensor companies, water utilities involved with novel sensor technologies, anticipate uncertainties regarding future acceptance of new monitoring approaches given the specific drinking water regulations and therefore struggle with how to proceed. Therefore, regulatory authorities and regulations have a strong influence, although they do not determine the direction of demand articulation. For some water utilities, the limited involvement of authorities and no new monitoring requirements constitute an argument for not engaging in activities and discussions on sensor technologies. Others, who are actively exploring possibilities for new sensor technologies, consciously postpone discussions on the position of new sensor technologies within regulatory schemes, but find themselves in impasses regarding future directions of sensor specifications and the embedding of novel sensors in the sector.

Clarification of regulatory schemes or adjustment to schemes can possibly move demand articulation processes further. Drinking water companies involved with sensor developments have a keen interest in involving authorities. During the workshop, participants suggested making the monitoring regimes less rigid regarding which parameters to be measured and how. This suggests that regulatory authorities may usefully shift from the shadow authority role to that of co-creating authority.

\subsection{Sensors for food and beverage quality}

\subsubsection{Driving forces in the domain and concerning technologies}

The food and beverages sector consists of a fragmented and extended value chain. International trade plays an important role; this implies that not only national (Dutch) regulation and standards are relevant for actors in this chain, but also regulation applicable in the countries to which products are shipped. Food quality and safety are part of a set of regulations that address the whole chain from 'farm 
to fork'. They include specific requirements regarding parameters and measurement principles, and regarding food hygiene in production facilities and food-product labeling. ${ }^{4}$ Food safety is seen as the responsibility of suppliers. Regulatory authorities verify whether food suppliers (producers, traders, catering industry) comply with national and European regulations. This implies that, in coordinating demand articulation, alignment between firms in the value chain and regulatory authorities is relatively more complex compared with the situation in the drinking water sector.

In addition to regulations by governmental authorities, there are standards, norms, and private schemes in place to regulate food quality and food safety (Trienekens and Zuurbier 2008; Van der Meulen 2011). A well-known scheme is the Codex Alimentarius, set up by an international forum including the World Health Organization (WHO), the Food and Agriculture Organization (FAO) of the United Nations and many countries. In particular, (big) retailers have been active in developing new regulations regarding food safety and quality in the form of private food regulations (Trienekens and Zuurbier 2008). Retailers, because of their position in the value chain and their market power, can force suppliers to comply with their standards (Havinga 2006). This implies that, in demand articulation processes, regulatory authorities are not the sole dominant point of reference regarding regulation. Given the actor constellation and the important role of commercial parties, we assume that regulators act as shadow or following authorities in demand articulation for new sensors in this domain.

New sensor or rapid test technologies are developed for a variety of monitoring purposes. Monitoring the quality of food includes controlling possible contamination of foods by microbes, pesticides, and other contaminants; detection of allergens; tracing the authenticity of a product (e.g. differentiating between horse and pig meat); monitoring cleaning processes; or verifying the ripeness of a product for consumption, harvesting, or storage. Monitoring can also be used during food processing, for testing incoming or intermediate products. At present, few micro-/nanotechnology-enabled monitoring technologies are applied in the food and beverages sector (Centro Nacional de Microelectrónica 2013).

\subsubsection{Legitimacy of new sensors}

Food safety is regarded as a priority in the sector, and specific contaminations such as Salmonella, Campylobacter, or Listeria are seen as important issues. Food incidents with fresh food products such as contaminated salmon attract widespread attention. In the course of the interviews and the workshops, a large variety of other quality issues were discussed that went beyond safety. Participating food companies and researchers emphasized food quality rather than food safety as a promising issue for novel sensor technologies. Food safety is assumed to be guaranteed, whereas food quality and also process optimization are associated with economic benefits (higher production values) and therefore more attractive. The introduction of sensors monitoring food safety could lead to questions regarding current food safety measurements; and some firms in the industry considered this to be undesirable according to interviewees. That said, companies observe that monitoring food safety with technologies has increased over the last 30 years. During the workshops, participants mentioned compliance with norms as an additional reason why food quality sensors might offer easier opportunities for sensor introduction. For food quality monitoring, sampling issues are less stringent and therefore sensors for food quality monitoring might be more feasible.
In the discourse on the overall need for, and legitimacy of, novel sensor technologies, regulatory authorities do not play a prominent role. It is mainly a discussion between suppliers and purchasers along the value chain. Regarding food safety, authorities emphasize that this is the responsibility of food companies and leave it to the companies how they organize this (with or without novel sensors). That said, policymakers and regulatory authorities are generally interested in novel monitoring technologies. Technologies that may help to reduce food spoilage, support food safety, and more quickly detect harmful contaminants are seen as interesting.

In the case of novel technologies that are more reliable and better than existing technologies, policymakers expect regulatory schemes to be adapted. In that respect, they position themselves as following, rather than as a forceful authority in demand articulation. Again here, the validation and certification of the new technologies is important. Sensor developers see certification of new measurement technologies as expensive. Developers and users will not easily pay for certification of such technologies. Sensor suppliers first want to ensure that they have paying customers in order to recover certification expenses. Customers like food retailers, however, want to wait for certified technologies before they purchase them. Furthermore, developers see certification of new sensors against reference norms as difficult, and new standards may be required. Sensor developers' and envisioned sensor users' assessments induce waiting games (Parandian et al. 2012).

The constellation in the food sector also introduces additional complexities regarding the desirability and need for new sensors. Purchasers of food or intermediate food products might value rapid tests or sensors to measure food quality parameters. This increased transparency in food quality is not always valued by suppliers, who fear that their products will not be purchased. A recurring question is which player(s) in the value chain benefit from these improved food quality measurements, who might feel disadvantaged and which player is willing to pay the costs for applying such technologies. Clearly, here regulations do not offer a strong reference point and there is only a weak, if any, shadow role in authorities' demand articulation.

4.2.3 Specification of requirements and involvement of authorities Food companies generally do not find it straightforward to specify requirements. An interviewed food company emphasized that it was difficult to decide which of the potential quality issues the firm should prioritize and would be in need of dedicated monitoring technologies, as there were so many possibilities. In that respect, demands are relatively fluid and even more difficult to characterize compared with the drinking water case. In the case of clear advantages for an individual company, sensors are seen as valuable. The identification of possible added value of new monitoring technologies is a matter not only of a sensor and its performance, but also of process optimization analyses. In other words, to assess the value of a possible sensor, firms need to have a clear idea of where (and how) they can optimize their processes. The workshop participants suggested that this process-focused approach might be extended across the whole value chain of a specific product. This also implies that, given the variety in food products and production facilities, a sensor's added value needs to be established on a case-by-case basis.

When food companies are discussing possible uses of sensors, issues around integration in processes, validation, and certification quickly come into play. What is striking here is that firms talk about requirements imposed by customers, e.g. compliance with specific 
standards, rather than requirements (only) imposed by regulatory agencies. If the measurement technologies do not comply with the existing standards, food product customers may not accept the supplying company's quality assurance approach. Thus, here we see a shadow of authority, although not of public agencies but rather of private actors and standardization organizations.

\subsubsection{Role of regulatory authorities}

In the case of food, regulatory authorities are less prominent players in demand articulation processes compared with the drinking water case. This is related to the characteristics of the domain: private goods and an extended value chain with strong international trade relationships. Business-to-business relationships are more important compared with the water case. Standards help to ensure a common (global) level of product quality and safety that supports international trade. Private actors close to consumers such as retailers play an important role in regulating food quality and safety.

The marginal role of regulatory authorities does not imply that they cannot exert a significant role in influencing and directing demand articulation in this domain. Regulatory agencies could take a more assertive role as a forceful authority and push for more extensive measurements across the whole product value chain in order to assure food quality and safety and reduce the workload for inspection authorities. At present, this is not the case, but some interviewed companies perceive this as a potential role. Companies referred to developments in the USA moving to such a more forceful authority role and to authorities emphasizing the food companies' own responsibility. Even if more measurements are not legally required, the shadow of authority of food safety agencies stimulates food companies to use new monitoring technologies at critical points in their processes.

\subsection{Sensors for soil quality}

\subsubsection{Driving forces in the domain and concerning technologies}

Ecogenomics is a scientific field that investigates the structure and function of genomes, e.g. of soil organisms, especially focusing on genetic mechanisms behind tolerance to, and production of, toxic contaminants. Improving insight into genetic mechanisms of soil organisms has a wide range of applications: for instance to increase productivity in agriculture, manage nature conservation projects, upcycle agricultural residues for bio-based industries and in general provide advice on cleaning contaminated sites. The latter forms the basis for spatial planning decisions and maps financial risks for project developers. The field of ecogenomics research aims to develop more efficient as well as eco-friendly tools that are able to determine soil health and general composition with a higher specificity. Here, we focus on two areas of application for these ecogenomics tools: nature conservation and agriculture for the production of consumable crops.

Potential users of the ecogenomics tools in nature conservation and agriculture are landowners and farmers. For contaminated sites, landowners together with (local) governments already use a soil risk assessment framework (Triade) based on bio-assays that combines insights from chemistry and biology (ecology and toxicology). The aim for farmers is to predict crop growth success based on soil composition and contaminants, and determine possible pollutants in produce. The outcomes of the tests on soil are compared with norms. Examples of norms are environmental regulations policing contaminated sites and the requirement to perform phytosanitary research when a farmer wants to sell his/her crops within the
European Union. The current Triade framework, however, is regarded as a heavy-weight and complex procedure, and the practice of analyzing bio-assays can be improved through the introduction of ecogenomics sensors and tools. Examples of such tools include genetic fingerprinting, which uses micro-arrays to determine differences in gene expressions of a soil sample compared to a model organism or benchmark. Other tools use phylogenetic and functional (geo)micro-arrays to map the functioning of a microbial community on a holistic scale.

The inspectorates are public organizations that execute national or EU government guidelines regarding crop and soil contamination and are financed by the sector itself. They currently use the Triade framework and could be future users of ecogenomics-based tools, alongside commercial laboratories. The farmers pay fees to the inspectorates for the inspections, and for research and validation of new tests. The EU determines the minimum standards and guidelines for phytosanitary research. Based on these, the inspectorates formulate inspection policies that are subsequently evaluated for approval by the sector. So, the inspectorates, even though they are the users of the tests, are governed by both policymakers and the sector, and are not the prime movers.

\subsubsection{Legitimacy of new sensors}

In demand articulation for ecogenomics-based sensors for soil risk assessment for nature conservation and agricultural applications, we see three main stakeholders: regulators, researchers and test users like inspectorates and farmers. They share an underlying value about working on soil, i.e. striving for sustainability through safeguarding soil health. Although this is regarded as a common, uncontested value, the workshop participants had different interpretations of what this meant for ecogenomics-based tools. First, they considered the notion of 'soil health' as ill-defined and open to a range of explanations. Second, they differed in their perspective on the speed of change brought about by applications enabled by ecogenomics R\&D. Some stakeholders, most notably the scientists, believed in short-term application of their findings, whereas others, such as regulators, envisaged a far more conservative and careful approach to introducing new test methods. Third, although many parties endorsed sustainable soil quality, they emphasized different aspects of sustainability, such as human health issues, crop yield or ecosystem health.

The third issue relates to the fact that different actors come from distinct application areas with associated values and priorities. Farmers for example want soil that yields as much produce as possible, while positively assessed by inspectorates. The Dutch national government regards human safety as a major reason to intervene in soil contamination, whereas human safety is not emphasized by private parties. The workshop participants discussed the need for a strong focus on human health. Some participants regularly pointed to the example of the 'child that plays in a sandbox', whereas others emphasized that humans were not expected to come into contact with soil that often. Thus, discussions about the ill-defined nature of soil health and quality, the speed of development of novel tools and reasons for introducing higher-specificity tools complicate the legitimacy of demands for sensors for soil health.

\subsubsection{Specification of requirements and involvement of authorities}

Further articulation of requirements regarding ecogenomics tools will then be complicated by the different and sometimes conflicting values and perspectives held by the actors involved. The workshop 
participants associated their needs regarding soil risk assessment and expectations regarding ecogenomics tools with various terms, such as 'screening', 'imaging', 'understanding', 'measuring', and 'predicting'. Participants stated that current ecogenomics tools are only able to measure soil substances. According to them, the crucial step would be to translate measurements into advice. That is, a tool would ideally provide substantial insight into how a measurement relates to soil health and how it should be interpreted. In general, causal relationships between detected soil values and outcomes can only be established when soils are followed for a long time or in a controlled laboratory environment. One way of doing this is for soil users to experiment with parameters to look for changes in outcomes, just like farmers testing the influence of different composting regimes.

In the workshop, ecogenomics researchers and agricultural consultancy firms disagreed about whether the translation is possible and whether ecogenomics tools can make valid claims regarding the relation between soil and the growth of organic compounds and soil life. The researchers emphasized their belief in producing sensors that can actually predict soil quality. Other workshop participants, such as regulators, warned that prediction is extremely difficult, because it requires benchmarking. They call for validation of novel ecogenomics tools in terms of scaling, i.e. how novel tools relate to other (existing) ecogenomics tools (complementary or competing) and how the tools fit in the current assessment framework. Normalization is regarded as needed but not currently feasible, because implementation and validation cannot go in parallel. If human risks are being assessed, in vitro or in vivo testing might also be required.

In addition to discussions about predictability, the issue of the sensitivity of the sensors was raised during the workshop. This issue also featured prominently in the case study of a knowledge instituteaffiliated start-up that developed an ecogenomics-based screening test to detect nematodes that can damage crops. Most laboratories test soil samples for nematodes by observing them with a microscope, but false positives and negatives are common. The new screening test is a polymerase chain reaction (PCR) test 'in a box'. The PCR toolbox is quicker, more robust and more sensitive. The question is, though, whether higher sensitivity is in line with the demands of farmers, inspectorates and commercial parties. The most important customers for the new screening tests for soil samples are laboratories that perform soil research for inspectorates as well as farmers. This soil research can be divided into two categories. The first is phytosanitary research, which is compulsory if farmers want to sell their products within the European Union and has to be performed under governmental inspectorate supervision. The second is voluntary research to give farmers insight into soil health. These results, however, do not have to be reported to the authorities, and this leads to a difference in focus by the laboratories and different articulated demands. The tests for voluntary research have to be as sensitive as possible with a high specificity, but, for phytosanitary research, the agriculture sector demands tests that are not too sensitive and deliver results just below the contamination threshold. Protecting trade is more important than tests with a higher sensitivity.

Finally, the different demands for causality and specificity have repercussions for the shifting alliances between researchers, farmers, policymakers, commercial laboratories, and the public inspectorates with their laboratories. The public inspectorates prefer to develop new tests themselves and buy knowledge from third parties only occasionally, because it is cheaper to perform tests themselves than to pay recurrent fees for a disposable toolbox. New tests 'in a box' would replace existing laboratory staff, who are on fixed contracts, and expensive laboratory equipment. Public inspectorates are now becoming quite involved with researchers and users, and consequently can be regarded as co-creating authorities.

\subsubsection{Role of regulatory authorities}

The case of ecogenomics tools for soil quality shows that regulatory authorities play different roles in demand articulation. In terms of nature conservation, the national ministry of the environment requires soil tests. The government also plays the role of landowner and user of tests. In terms of agriculture, the national ministry of the environment and its EU counterparts determine the sensitivity of the soil health tools by proxy through regulations with regard to food safety and quality. The sector, i.e. the farmers themselves, are the prime movers in demand articulation. So, policymakers involved in regulation have a minimal role in specifying the requirements for ecogenomics-based tools for soil quality assessment. Currently, regulating bodies are in the shadow.

Simultaneously, the inspectorates, which play an executive role in the regulation of soil quality, are more involved in the demand articulation process. They are involved in the development, adaptation, and implementation of new ecogenomics-based soil evaluation tools that are more precise and cost-effective for farmers and governmental inspection agencies. Although inspectorates are not influential in governmental bureaucracy and therefore not involved in demand articulation on that level, they do act as co-creating authorities in the development of new ecogenomics-based tests.

\section{Conclusions}

This article sets out to answer the question of the extent to which and how regulatory authorities influence demand articulation processes. To this end, we conceptualized roles of regulatory authorities and used this to examine demand articulation in our case studies. In all our cases, we observed that regulatory authorities were relatively little engaged in demand articulation, except for the executive public organizations involved in the case on soil quality. We found that, even if the regulatory authorities were by and large little involved, they still exerted influence. In particular, the shadow authority role was found repeatedly in our cases. We also found instances of other roles such as co-creating and following authorities, although less prominently.

Regulatory actors' involvement through their shadow of authority was visible in at least two ways. First, we observed a recurrent pattern in discussions and anticipations of suppliers and potential sensor users on the need for, and legitimacy of, the new sensor technologies in general. Users reflected on the relation between novel sensors and the overall monitoring regime as required by authorities. The legitimacy of the use of sensors was to some extent contested in cases where they did not easily fit within the existing regime. Users' and producers' projections regarding authorities' current and possible future positions on sensors influenced whether these users and producers signaled a demand for sensors at all. Our cases also showed that regulatory regimes and authorities' positions did not fully determine users' and producers' preferences, given the observed diverging sets of preferences, emphasizing commercial rather than public interests.

A second recurring pattern relating to the shadow of authority involves discussions and anticipations of the relation between 
requirements of specific novel sensor applications, their validation and certification, and regulation. The proof of a sensor's or a test's validity is particularly important in cases where authorities prescribe specific measurement procedures. To prove the test's validity, research needs to be done to compare the new sensor with the existing ways of measuring. This may be difficult in cases where novel sensors imply different measurement principles than the standardized tests. Pursuing such validity trials is difficult because of a lack of interest, resources or incentives on the part of involved users. This could lead to waiting games and de facto lock-in situations that favor the older over the new tests.

Our case studies suggest that the degree to which regulatory actors become involved with, and influence, demand articulation is likely to depend upon a number of conditions. First, the degree of specification of regulatory frameworks affects the strength of the guiding or steering influence of regulatory authorities on demand articulation process. There is less room for variety in cases where regulations are very explicit regarding for example location and frequency of measurements, types of measurement to be done and procedures to be followed. Second, the relationship between regulatory actors and the (regulated) field is important. In cases where authorities leave matters to a sector (e.g. self-regulation), their influence is less strong compared with cases where there is a more hierarchical form of governance. In some cases, such as situations where products have a public or common good character, like surface water or soil, public authorities have a relatively more important position in these matters compared with situations where products are produced and traded in the private realm, like food. However, in situations with large public unrest or confusion, such as with GMOs or food, public pressure will force regulatory actors to be more involved. Third and related, the complexity of actor constellations in a particular field is likely to influence the effect of regulatory actors, particularly in cases where there is no strong form of hierarchical governance present. In situations of complex actor constellations with many interested parties, such as the food case, governmental actors are indeed one among many who may have particular preferences regarding new and emerging technologies. In the case of food, interestingly, private actors such as retailers and retail standards fulfilled the authorities' shadow role. In sum, specification of regulatory schemes, regulatory agencies' relationships with their fields and actor constellations modulate effects of regulatory actors' involvement with demand articulation processes.

Authorities' shadow significantly impacts the demand articulation process. To what extent this is an artifact of our case study selection of highly regulated fields or is more broadly applicable requires further research. Given the important role of legal requirements, we are convinced that the conceptual framework (Fig. 1) is more broadly applicable and that the shadow of authority is likely to be observed in other cases. Further research that compares and contrasts regulatory authorities' involvement and effects across technological domains would add to our understanding of authorities' role in demand articulation. For example, different user-producer interactions and constellations can explain differences across sectors. As this study was limited to examining demand articulation processes in an early phase of the innovation journey, further longitudinal research is required to examine whether authorities' role or modes of involvement change over time. Such a longitudinal study could then also examine authorities' effects and (relative) influence over the whole demand articulation process, up to the purchase and implementation of new technologies, and might see the role of authorities shifting from one quadrant to another in the conceptual model.
Our study suggests some recommendations for demand-based innovation policies. Actors in our case studies called for a stronger involvement by regulatory authorities (a co-creating authority as we call it in our conceptualization), as they set important conditions for the final use of such applications; this in turn influences users' requirements and preferences for novel technologies. In the workshops and interviews, specific suggestions were made, such as the development of less rigid regulatory regimes that would be more conducive to demand articulation for novel technologies. Suggestions referred not only to enabling thinking on alternative monitoring approaches, but also to giving direction regarding the substance of such monitoring technologies. For instance, in the water sector, references were made to conceptualizing monitoring more in terms of health-related than process-related parameters. The strong call for regulatory requirements is backed up by the potential beneficial role of regulation as suggested by Porter and Van de Linde (1995). Clarity on requirements as set out in regulations reduces uncertainty for technology producers and users, and sets a level playing field for all actors. At the same time, it may induce early and possibly undesirable lock-ins.

In conclusion, we suggest bringing regulatory actors out of the shadows, in practice as well as in discussions on demand-based innovation policies. The first reason for doing so is to support demand articulation processes and conditions for user-producer interactions to overcome possible impasses or waiting games. The second reason is to influence the cognitive part or substance of demands, which hitherto is less highlighted in the demand-based innovation policy literature as this literature tends to focus on conditions and processes enabled by public actors.

\section{Funding}

Haico te Kulve and Kornelia Konrad's contributions are supported by NanoNextNL, a micro and nanotechnology consortium of the Government of the Netherlands and 130 partners. Tjerk Jan Schuitmaker's contribution is supported by the BE-Basic consortium.

\section{Notes}

1. We understand innovation processes as the 'invention, development, and implementation of new ideas' [4: 776].

2. In this paper, we limit ourselves to identifying roles of regulatory authorities and their effects on demand articulation. The rationales and mechanisms that influence why and how authorities become involved is a topic for further investigation.

3. See http://wetten.overheid.nl/BWBR0030152/2015-11-28.

4. See EU regulations 852/2004, 853/2004, 854/2004, 2073/2005.

\section{References}

Ambec, S., Cohen, M. A., Elgie, S., and Lanoie, P. (2013) 'The Porter Hypothesis at 20: Can Environmental Regulation Enhance Innovation and Competitiveness?', Review of Environmental Economics and Policy, 7/1: $2-22$.

Blind, K. (2016) 'The Impact of Regulation on Innovation', in J. Edler, P. Cunningham, A. Gök and P. Shapira (eds) Handbook of Innovation Policy Impact, pp. 450-82. Edward Elgar: Cheltenham, UK.

Boon, W. P. C., and Edler, J. (2018) 'Demand, Challenges and Innovation. Making Sense of New Trends in Innovation Policy', Science and Public Policy, 45/4: 435-47.

—, Moors, E. H. M., Kuhlmann, S., and Smits, R. E. H. M. (2008) 'Demand Articulation in Intermediairy Organisations: The Case of Orphan 
Drugs in the Netherlands', Technological Forecasting \& Social Change, 75: 644-71.

Börzel, T. A., and Risse, T. (2010) 'Governance without a State: Can it Work?', Regulation \& Governance, 4: 113-34.

Centro Nacional de Microelectrónica. (2013) Report on Existing Applications of Microsystems in the Food Sector. FoodMicroSystems Project, <http:// www.foodmicrosystems.eu/? page_id=1159> accessed 10 January 2017.

Christensen, C. M. (1997) The Innovator's Dilemma: When New Technologies Cause Great Firms to Fail. Harvard Business School Press: Boston, Massachusetts.

Deuten, J. J., Rip, A., and Jelsma, J. (1997) 'Societal Embedding and Product Creation Management', Technology Analysis \& Strategic Management, 9/2: $131-48$.

Edler, J. (2013) 'Review of Policy Measures to Stimulate Private Demand for Innovation. Concepts and Effects', in L. Macgregor, T. Prosser and C. Villiers (eds) (2000) Compendium of Evidence on the Effectiveness of Innovation Policy Intervention, Introduction'. Manchester Institute of Innovation Reserach, The University of Manchester: Manchester, UK.

- and Georghiou, L. (2007) 'Public Procurement and Innovation Resurrecting the Demand Side', Research Policy, 36: 949-63.

Fleck, J. (1988) 'Innofusion or Diffusation? The Nature of Technological Development in Robotics. Edinburgh PICT Working Paper No. 7'. Edinburgh University.

Garud, R., and Ahlstrom, D. (1997) 'Technology Assessment: a Socio-Cognitive Perspective', Journal of Engineering and Technology Management, 14: 25-48.

— Embedded Agency in Technology Entrepreneurship', Research Policy, 32: 277-300.

— , and Rappa, M. A. (1994) 'A Socio-Cognitive Model of Technology Evolution: The Case of Cochlear Implants', Organization Science, 5/3: 344-62.

— J Jain, S., and Kumaraswamy, A. (2002) 'Institutional Entrepreneurship in the Sponsorship of Common Technological Standards: the Case of Sun Microsystems and Java', Academy of Management Journal, 45/1: 196-214.

— Tuertscher, P., and Van de Ven, A. H. (2013) 'Perspectives on Innovation Processes', The Academy of Management Annals, 7/1: 775-819.

Georghiou, L., and Harper, J. C. (2011) 'From Priority-Setting to Articulation of Demand: Foresight for Research and Innovation Policy and Strategy', Futures, 43/3: 243-51.

Gerard, D., and Lave, L. B. (2005) 'Implementing Technology-Forcing Policies: The 1970 Clean Air Act Amendments and the Introduction of Advanced Automotive Emissions Controls in the United States', Technological Forecasting \& Social Change, 72: 761-78.

Havinga, T. (2006) 'Private Regulation of Food Safety by Supermarkets', Law o Policy, 8/4: 515-33.

Hegger, D. L. T., Spaargaren, G., Van Vliet, B. J. M., and Frijns, J. (2011) 'Consumer-Inclusive Innovation Strategies for the Dutch Water Supply Sector: Opportunities for more Sustainable Products and Services', NJAS Wageningen Journal of Life Sciences, 58: 49-56.

Hillman, A. J., Keim, G. D., and Schuler, D. (2004) 'Corporate Political Activity: A Review and Research Agenda', Journal of Management, 30/6: $837-57$.

Jaffe, A. B., Newell, R. G., and Stavins, R. N. (2002) 'Environmental Policy and Technological Change', Environmental and Resource Economics, 22/1-2: 41-70.

Kemp, R., and Pontoglio, S. (2011) 'The Innovation Effects of Environmental Policy Instruments - A Typical Case of the Blind Men and the Elephant?', Ecological Economics, 72/December: 28-36.

Leonard-Barton, D. (1988) 'Implementation as Mutual Adaptation of Technology and Organization', Research Policy, 17: 251-67.

Lowe, N., and Feldman, M. (2008) 'Constructing Entrepreneurial Advantage: Consensus Building, Technological Uncertainty and Emerging Industries', Cambridge Journal of Regions, Economy and Society, 1/2: $265-84$.
Macgregor, L., Prosser, T., and Villiers, C. (2000) 'Introduction'. In L. Macgregor, T. Prosser and C. Villiers (eds) Regulation and Markets Beyond 2000, Ashgate: Dartmouth/Aldershot.

Martin, P. (2001) 'Great Expectations: the Construction of Markets, Products and User Needs during the Early Development of Gene Therapy in the USA'. In R. Coombs, K. Green, A. Richards and V. Walsh (eds.) Technology and the Market: Demand, Users and Innovation, pp. 38-67. Edward Elgar: Cheltenham.

Mazzucato, M. (2013) The Entrepreneurial State: Debunking Public vs Private Sector Myths. Anthem Press: London, New York.

McMeekin, A. (2001) 'Shaping the selection environment: "chlorine in the dock", in R. Coombs, K. Green, A. Richards and V. Walsh (eds.) Technology and the Market: Demand, Users and Innovation, pp. 112-35. Edward Elgar: Cheltenham, UK.

Munir, K. A., and Philips, N. (2005) 'The Birth of the "Kodak Moment": Institutional Entrepreneurship and the Adoption of New Technologies', Organization Studies, 26/11: 1665-87.

North, D. C. (1984) 'Transaction Costs, Institutions and Economic History', Journal of Institutional and Theoretical Economics, 140: 34-49.

OECD (2005) Oslo Manual. Guidelines for Collecting and Interpreting Innovation Data. OECD \& Eurostat: Paris.

- (2011) Demand-side Innovation Policies. OECD Publishing: Paris.

Oliver, C., and Holzinger, I. (2008) 'The Effectiveness of Strategic Political Management: a Dynamic Capabilities Framework', Academy of Management Review, 33/2: 496-520./

Parandian, A., Rip, A., and Te Kulve, H. (2012) 'Dual Dynamics of Promises, and Waiting Games Around Nanotechnologies', Technology Analysis \& Strategic Management, 24/6: 565-82.

Porter, M. E., and Van der Linde, C. (1995) 'Toward a New Conception of the Environment - Competitiveness Relationship', Journal of Economic Perspectives, 9/4: 97-118.

Rip, A. (1995) 'Introduction of New Technology: Making Use of Recent Insights from Sociology and Economics of Technology', Technology Analysis \& Strategic Management, 7/4: 417-31.

- (2006) 'Folk Theories of Nanotechnologists', Science as Culture, 15/4: 349-65.

— and Te Kulve, H. (2008) 'Constructive Technology Assessment and Socio-Technical Scenarios'. In E. Fisher, C. Selin and J.M. Wetmore (eds) The Yearbook of Nanotechnology in Society, Volume 1: Presenting Futures, pp. 49-70. Springer Netherlands: Dordrecht

- Misa, T., and Schot, J. (1995) Managing Technology in Society. The Approach of Constructive Technology Assessment. London/New York: Pinter Publishers.

Scharpf, F. W. (1994) 'Games Real Actors could Play: Positive and Negative Coordination in Embedded Negotiations', Journal of Theoretical Politics, 6/1: 27-53.

(1997) Games Real Actors Play: Actor - Centered Institutionalism in Policy Research. Westview Press: Boulder, CO/Oxford.

Schot, J., and Rip, A. (1997) 'The Past and Future of Constructive Technology Assessment', Technological Forecasting and Social Change, 54/2/3: 251-68.

Te Kulve, H. (2010) 'Emerging Technologies and Waiting Games: Institutional Entrepreneurs Around Nanotechnology in the Food Packaging Sector', Science, Technology \& Innovation Studies, 6/1: 7-31.

_ and Konrad, K. (2017) 'The Demand Side of Innovation Governance: Demand Articulation Processes in the Case of Nano-based Sensor Technologies'. In D. Bowman, E. Stokes and A. Rip (eds) Embedding New Technologies into Society: A Regulatory, Ethical and Societal Perspective, pp.159-186, Singapore: Pan Stanford Publishing.

- and Rip, A. (2011) 'Constructing Productive Engagement: Pre-engagement Tools for Emerging Technologies', Science and Engineering Ethics, 17/4: 699-714.

Trienekens, J., and Zuurbier, P. (2008) 'Quality and Safety Standards in the Food Industry, Developments and Challenges', International Journal of Production Economics, 113: 107-22.

Tripsas, M. (2008) 'Customer Preference Discontinuities: A Trigger for Radical Technological Change', Managerial and Decisions Economics, 29: 79-97.

Van de Poel, I. (2003) 'The Transformation of Technological Regimes', Research Policy, 32: 49-68. 
Van den Broeke, J., Carpentier, C., Moore, C., Carswell, L. et al. (2014) Compendium of Sensors and Monitors and their Use in the Global Water Industry. Water Environment Research Foundation: Alexandria, VA.

Van der Kooij, D., Van Genderen, J., Heringa, M., Hogenboom, A. et al. (2010) Drinkwaterkwaliteit Q21: een Horizon voor Onderzoek en actie. KWR Watercycle Research Institute: Nieuwegein, the Netherlands.

Van der Meulen, B. M. J. (ed.) (2011) Private Food Law: Governing Food Chains through Contract law, Self-regulation, Private Standars, Audits and
Certification Schemes. Wageningen Academic Publishers: Wageningen, the Netherlands.

van Merkerk, R. O., and van Lente, H. (2005) 'Tracing Emerging Irreversibilities in Emerging Technologies: The Case of Nanotubes', Technological Forecasting and Social Change, 72/9: 1094-111.

Weber, M. K., and Rohracher, H. (2012) 'Legitimizing Research, Technology and Innovation Policies for Transformative Change', Research Policy, 41/6: $1037-47$. 